\title{
PERANCANGAN BRANDING IDENTIY SEBAGAI MEDIA PROMOSI UNTUK UMKM SALAD BUAH BERKAH JAYA
}

\author{
Reva Havanda Hartland Setyabudhi ${ }^{1)}$ \\ Desain Komunikasi Visual Universitas Ma Chung \\ 331610013@student.machung.ac.id
}

\begin{abstract}
Abstrak
Salad buah adalah salah satu makanan atau cemilan yang populer pada saat ini. Salah satunya yaitu produk dari "Berkah Jaya" Salad Buah . "Berkah Jaya" Salad Buah terdapat di Kota Balikpapan. Namun berdasarkan dengan identifikasi masalah, didapatkan hasil belum mempunyai brand identity hingga kurangnya dalam promosi, sehingga perlu adanya perancangan brand identity serta promosi yang digunakan untuk meningkatkan brand awerness di benak masyarakat. Metode penelitian ini menggunakan metode analisis SWOT, sehingga menghasilkan perancangan brand identity dan media promosi untuk mengenalkan produk "Berkah Jaya" Salad Buah kepada masyarakat. Konsep perancangan ini menggunakan gaya yang menarik serta simpel agar bisa masuk untuk semua umur khususnya untuk orang dewasa. Dari perancangan ini diharapkan produk ini dapat mendapatkan keuntungan yang lebih dan bisa meningkatkan brand awerness kepada masyarakat. Hasil yang didapatkan dari perancangan ini berupa logo, media promosi baik online maupun offline dan buku GSM sebagai panduan mengenai umkm "Berkah Jaya" Salad Buah.
\end{abstract}

Kata Kunci: Salad buah, Brand Identity, Logo

\begin{abstract}
Abstrac
Fruit salad is one of the foods or snacks that are popular at this time. One of them is a product of "Berkah Jaya" Salad Buah. "Berkah Jaya" Salad Buah can be found in Balikpapan City. However, based on the identification of the problem, the results obtained do not have a brand identity to the lack of promotion, so it is necessary to design a brand identity and promotion that is used to improve brand awareness in the minds of the public. This research method uses SWOT analysis, resulting in brand identity design and promotional media to introduce the product "Berkah Jaya" Salad Buah to the public. This design concept uses an attractive and simple style so that it can fit all ages, especially for adults. From this design it is hoped that this product can get more benefits and can increase brand awareness to the community. The results from this design are logo, the presence of promotional media both online and offline and a GSM book as a guide regarding the Umkm "Berkah Jaya" Salad Buah.
\end{abstract}

Keywords: Fruit salad, Brand Identity, Logo. 


\section{PENDAHULUAN}

UMKM sangatlah penting keberadaannya di Indonesia karena selain dapat menambah pendapatan, UMKM juga dapat mengurangi jumlah pengangguran di Indonesia (Susila, 2017). Sebagai orang Indonesia tentu pemandangan dan aktivitas kita sehari-hari tak lepas dari berbagai layanan dan barang hasil kreasi pelaku UMKM. Adapun di era digital saat ini, bahkan ada pula yang tidak memiliki toko serta hanya memasarkan produknya secara online, dan belum memiliki perizinan usaha. Perekonomian selama 2015-2018 telah berubah secara nyata untuk mensejahterahkan rakyat menuju zero poverty dan menghapuskan ketimpangan. Mengakhiri masa bakti Kabinet Kerja Presiden Joko Widodo tahun 2019, pemerintah telah berhasil membangun fondasi pembangunan yang tahun 2016 meningkat pertumbuhannya mencapai 26.09 persen. Hal ini dikarenakan di tahun 2015-2016 turunnya harga batu bara yang memberikan dampak pertumbuhan ekonomi kaltim di dua tahun menurun. Namun pengembangan UMKM bukan tanpa kendala. Kendala yang dihadapi UMKM Kaltim di kesulitan pemasaran, akses ke sumber pembiayaan yang sangat terbatas, keterbatasan sumber daya manusia (SDM), kesulitan bahan baku, dan keterbatasan inovasi dan teknologi. Sehingga dibutuhkan peran penting dari pemerintah untuk memberikan solusi yang tepat serta dukungan untuk mengatasi permasalahan UMKM tersebut. Dari tahun 2012-2018 atau selama enam tahun terdapat 21.140 UMKM yang tersebar di enam kecamatan di Balikpapan. Diharapkan perancangan brand identity ini dapat membantu pelaku usaha untuk mengembangkan Umkm secara berkelanjutan sekaligus mendukung keberhasilan program pemerintah dalam melakukan pertumbuhan Umkm sebagai penyangga ekonomi pelaku usaha. Berdasarkan alasan-alasan tersebut, penulis tertarik untuk melakukan perancangan dengan judul "Perancangan branding berkesinambungan melalui infrastructure leads growth. Pada tahun 2018, pertumbuhan ekonomi sebesar 5.04\%. Inflasi pada tahun 2018 hanya $2.88 \%$ dengan rata-rata $3.20 \%$. Inflasi yang rendah ini menunjukkan peningkatan daya beli masyarakat. Tingkat kemiskinan terus menurun satu digit, menjadi $9,66 \%$ atau $25.56 \%$ juta orang. Tingkat penggangguran juga terus menurun menjadi $5.35 \%$ pada tahun 2018 dan pemerataan pendapatan semakin membaik yang ditunjukkan oleh Gini Ratio menjadi 0.381 dari 0.414 pada tahun 2014 (Kementrian Koperasi dan UKM RI, 2019). Di Kalimantan Timur sendiri menurut Badan Pusat Statistik (BPS) Kaltim mencatat, pertumbuhan UMKM di triwulan kedua tahun lalu mengalami peningkatan sebesar 10,3 persen sehingga sejak identity sebagai media promosi Umkm "Berkah Jaya" Salad Buah.

\section{TINJAUAN PUSTAKA}

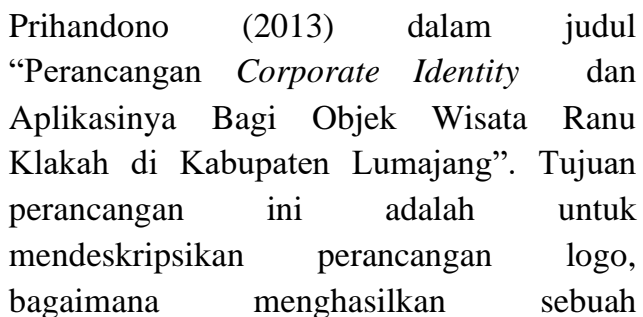
perancangan corporate identity yang efektif dan komunikatif beserta dengan aplikasinya sebagai upaya untuk membangun citra Wisata Ranu Klakah, sehingga dapat meningkatkan kunjungan wisata. Media pendukung yang dipakai berupa seperti buku GSM (Guide Standard Manual, brosur, $x$ banner, map, amplop, kop surat, label disc, sign system, leaflet, seragam, kaos, dan poster. Dari artikel ilmiah tersebut, didapatkan masukan bagi perancangan yang dilakukan berupa: 1) perancangan tipografi; 2) perancangan corporate identity.

Rishan, dkk. (2017) dalam judul "Perancangan Corporate Identity CV.Inti Calcium" tujuan perancangan ini adalah merancang Corporate Identity yang sesuai dan efisien bagi perusahaan CV. Inti Calcium. Media pendukung yang digunakan 
nama, kop surat, amplop surat, map A4, notes, nota, mug, kalender, tumbler, pin, signage, bolpoin, x-banner, seragam vehcle identity, dan stempel. Dari artikel ilmiah tersebut didapatkan yaitu 1) menuangkan visi dan keistimewaan CV. Inti Calcium kedalam suatu karya desain

Raditya (2014) dalm judul "Perancangan branding "Marilyn's Cake"”. Tujuan perancangan ini adalah menyusun dan merencanakan strategi branding yang efektif dan menarik sehingga mampu menciptakan brand awareness di benak masyarakat mengenai usaha Marilyn's Cake. Media pendukung yang digunakan berupa packaging, flyer, brosur, website, media sosial, merchandise, vehcle identity, serta greeting card dan gift card. Dari artikel tersebut, didapatkan masukan berupa 1) bagaimana menciptakan brand awerness di benak masyarakat; 2) dapat meningkatkan angka penjualan dan profit usaha.

Ghazali (2015) dalam judul "perancangan visual branding kawasan agrowisata condet" perancangan ini bertujuan untuk upaya pemecahan masalah untuk menggembangkan dan memberdayakan potensi agrowisata yang ada sehingga dapat meningkatkan eksistensi dan menyelamatkan aset berharga Condet. Dari artikel tersebut didapatkan berupa 1) meningkatkan daya tarik tinggi berupa visual branding sebagai media pendekatan aset berharga daerah.

Purba (2015) dalam judul "Perancangan Branding Lokananta Sebagai Digital Library Pertama Museum di Indonesia". Tujuan perancangan tersebut adalah menciptakan branding Lokananta sebagai digital library pertama museum di indonesia. Dari artikel ilmiah tersebut, didapatkan masukan bagi perancangan berupa 1) menciptakan sebuah media berupa digital library yang diunggah ke dalam bentuk website yang memuat seluruh data Lokananta dalam format apapun.

\section{METODE PERANCANGAN}

Metode perancangan dalam penelitian ini adalah menggunakan metode kualitatif deskriptif dengan mendeskripsikan tentang analisis "Perancangan Brand Identity Untuk Umkm "Berkah Jaya" Salad Buah Sebagai Media Promosi". Tahapan dan pengumpulan data berupa observasi, wawancara, kuisioner, studi pustaka, dan dokumentasi. Analisis data dan sintesis konsep menggunakan analisis SWOT (Strenghs, Weakness, Opportunities, Thereats) dan matriks SWOT dari empat faktor strategi yaitu strategi S-O, strategi W-O, strategi S-T dan strategi W-T kemudian dilanjutkan dengan pra produksi, produksi, dan pasca produksi yang mengahsilkan media promosi sebagai media pendukung "Berkah Jaya" Salad Buah.

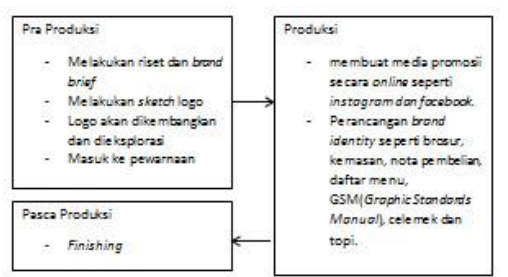

Gambar 1. Bagan Strategi Perancangan

\section{HASIL DAN PEMBAHASAN}

\subsection{Pengumpulan dan Analisis Data}

Untuk merancang brand identity Umkm "Berkah Jaya" Salad Buah diperlukan beberapa informasi tentang perusahaan dan produk yang dijual. Informasi tersebut diperlukan sebagai arahan untuk menentukan strategi, baik dalam visualisasi maupun promosi. Pengumpulan data juga dilakukan untuk mengetahui informasi dan kesan apa yang ingin disampaikan kepada calon konsumen "Berkah Jaya" Salad Buah melalui brand identity yang dirancang. Hal tersebut diperlukan agar brand identity yang dirancang dapat menyampaikan pesan dan dapat menyelesaikan masalah yang dihadapi dengan efektif. Pengumpulan data dalam perancangan ini dilakukan berupa observasi kompetitor yang menjual serupa yaitu Sour Sally, Kecut Manis, dan Salad nyoo yang 
sudah memiliki brand yang cukup kuat. Data yang diperoleh dari proses pengumpulan data adalah visualisasi desain dan media promosi yang digunakan serta outlet dari Sour Sally, Kecut Manis, dan Salad nyoo.

\subsection{Analisis Data}

Analisis data yang digunakan pada perancangan ini menggunakan metode kualitatif dan analisis SWOT. Tujuannya adalah untuk mendapatkan informasi dari analisis situasi dan memisahkannya dalam pokok persoalan internal (Kekuatan dan kelemahan) dan pokok persoalan eksternal (peluang dan ancaman). (Riadi, 2013). Setelah mendapatkan hasil dari analisis SWOT dilanjutkan dengan matriks SWOT. matriks SWOT digunakan untuk menyusun strategi organisasi atau perusahaan yang menggambarkan secara jelas peluang dan ancaman yang dihadapi organisasi/perusahaan sehingga dapat disesuaikan dengan kekuatan dan kelemahan organisasi/perusahaan. Matriks ini menghasilkan empat kemungkinan alternatif strategi yaitu strategi S-O, strategi W-O, strategi S-T. Dan strategi W-T (Rangkuti, 2015). Berdasarkan analisis SWOT dan matriks SWOT yang dilakukan, "Berkah Jaya" Salad Buah memiliki permasalahan utama yaitu belum memiliki brand identity, media promosi yang digunakan kurang dan banyaknya perusahaan yang serupa yang memiliki brand kuat sehingga diperlukan adanya brand identity dan media promosi yang digunakan dengan tujuan meningkatkan minat masyarakat untuk makan buah-buahan namun dengan cara yang menyenangkan.

\subsection{Sintesis Konsep}

Perancangan ini berdasarkan dari analisis SWOT, matriks SWOT, observasi, dan wawancara yang dilakukan. Hasil yang didapat dari permasalahan utama Umkm "Berkah Jaya" Salad Buah adalah belum memiliki brand identity dan media promosi yang digunakan masih kurang maka diperlukan adanya logo sebagai brand identity dan media promosi yang digunakan baik online maupun offline sehingga "Berkah Jaya" Salad Buah dapat dikenali oleh masyarakat luas dan menjadi produsen salad buah yang memiliki brand identity dengan tujuan untuk meningkatkan masyarakat gemar makan buah dengan cara yang menyenangkan. Perancangan yang dilakukan mengikuti brand brief dengan konsep simpel dan memberikan kesan fun dengan harapan dapat diterima oleh masyarakat luas serta mengikuti strategi perancangan mulai dari pra produksi, produksi dan pasca produksi. Konsep perancangan ini akan diterapkan kedalam buku GSM (Graphic Standard Manual) yang mencakup latar belakang brand dan media promosi yang digunakan baik online dan offline.

\subsection{Pra Produksi}

Perancangan ini dimulai dari membuat moodboard untuk menemukan konsep yang sesuai dengan keinginan dari pemilik "Berkah Jaya" Salad Buah ide yang didapatkan adalah dari penggunaan warna untuk logo, font yang dipakai untuk berbagai macam material baik untuk logotype, penggunaan pada brand identity hingga penulisan untuk GSM(Graphic Standard Manual). Setelah itu beberapa referensi logo dan brand identity serta penggunaan supergraphic yang akan dipakai oleh "Berkah Jaya" Salad Buah.

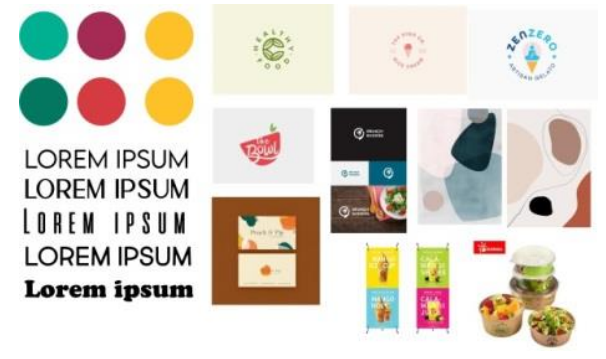

Gambar 2. Moodboard

\subsubsection{Logo}

Setelah mengetahui konsep yang akan dipakai yaitu simple tetapi memberikan 
kesan fun, Selanjutnya penulis membuat sketch logo dengan jumlah 20 untuk mengetahui logo mana yang cocok dan mengikuti konsep dari "Berkah Jaya" Salad Buah.

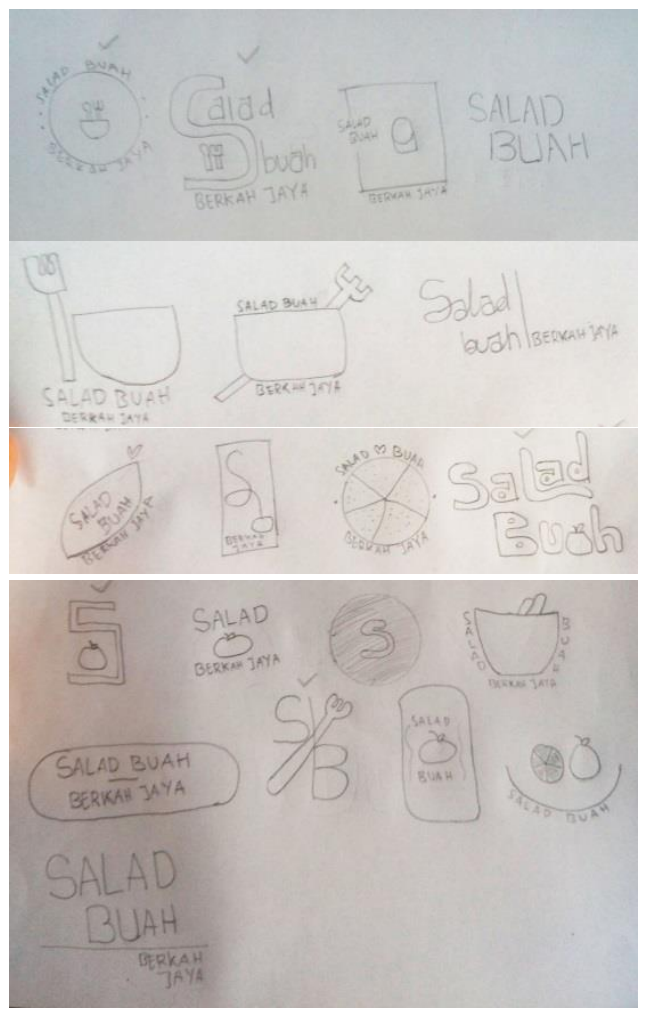

Gambar 3. Sketch Logo

Setelah melakukan 20 sketch logo selanjutnya memilih lima dari 20 sketch logo dan dijadikan hasil digital untuk mejadi logo alternatif dan akan dipilih satu untuk dikembangkan lebih banyak untuk mencari yang cocok. Setelah melakukan sketch logo dan membuat lima logo alternatif, Selanjutnya logo yang sudah terpilih akan dikembangkan dalam beberapa macam model logo dan dipilih tiga dari beberapa logo yang berbeda

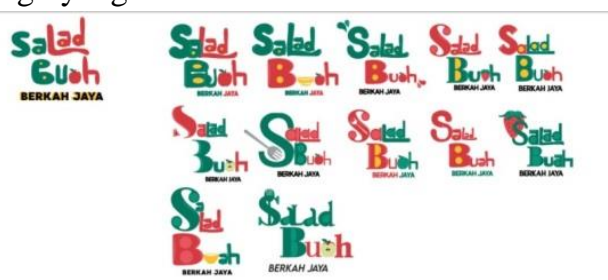

Gambar 5. Explore Logo
Setelah dikembangkan menjadi lebih rapi dan terkonstruksi maka logo ini menjadi logo resmi dari produk Salad Buah "Berkah Jaya". Konsep visual dari logo ini adalah gaya yang simple dan memberikan kesan fun. Terlihat dari tiap-tiap huruf menggunakan bentuk bubble serta penggunaan ornamen yaitu buah apel dan splash untuk memberikan kesan fresh dan berkualitas. Penggunaan warna pada logo adalah merah dan hijau. Warna merah merepresentasikan membangkitakan selera makan dan merangsang nafsu makan serta untuk menarik perhatian calon konsumen dan warna hijau merepresentasikan ramah lingkungan dan sehat.

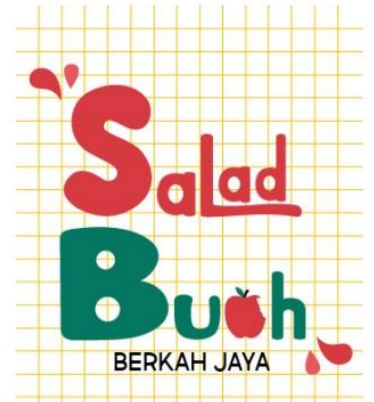

\section{Gambar 6. Logo Sebelum Revisi}

Namun untuk logo yang sebelumnya ada beberapa kekurangan seperti belum adanya grid system dan perubahan nama yang baru lebih menekankan nama tempat yang menjual produk tersebut dan melakukan revisi ulang dan terciptalah logo baru dengan adanya grid system dan ukuran jarak tulisan dengan elemen yang dipakai yaitu apel dan drops.
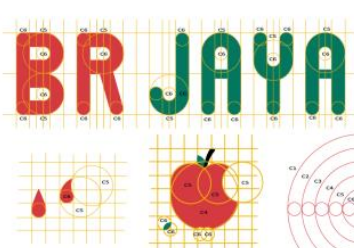

Gambar 7. Logo dengan Grid System 


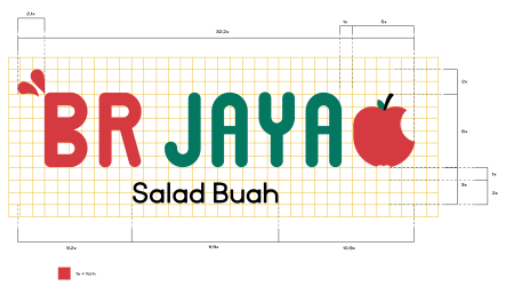

Gambar 7. Jarak tulisan dengan elemen 4.2.4 Tipografi

Tipografi yang digunakan dalam logo sebagai keterangan nama produk dengan jenis sans serif dengan font "Market Fresh". Font ini memiliki kesan yang simple tapi tetap fun dan modern, sehingga font ini cocok dengan konsep yang dipakai untuk produk Salad Buah "Berkah Jaya"

\section{MARKET FRESH FONT FAMILY}

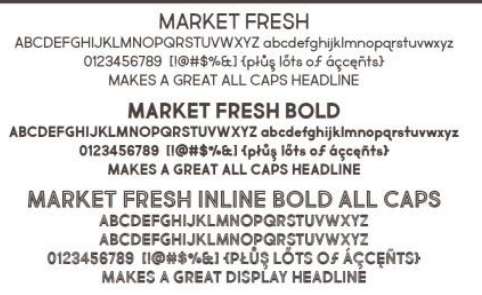

Gambar 8. Tipografi Produk

\subsubsection{Color Pallatte}

Warna yang diterapkan oleh "Berkah Jaya" Salad Buah sebagai warna identitas produk terdiri dari 3 macam warna yaitu merah, hijau dan kuning yang dibagi sebagai warna primer dan sekunder. Warna primer yang digunakan oleh "Berkah Jaya" Salad Buah yang pertama adalah warna hijau dengan pantone $710 \mathrm{C}$ dimana merupakan wana merah yang merepresentasikan membangkitkan selera makan. Sedangkan warna primer kedua yaitu warna hijau dengan pantone $3295 C$, warna tersebut merepresentasikan menyehatkan. Sedangkan warna sekunder yaitu warna kuning dengan pantone $7549 C$ yang merepresentasikan sama dengan warna merah yaitu membangkitkan selera makan dan merangasang nafsu makan. warna primer digunakan sebagai warna utama, sedangkan di berbagai media yang tidak memungkinkan untuk menggunakan warna primer dapat beralih menggunakan warna sekunder sebagai alternatif. Namun jika tidak memungkinkan menggunakan ketika warna tersebut dapat pula menggunakan warna yang mirip dan memiliki kecocokan seperti warna merah muda, oranye, dan lainlain.

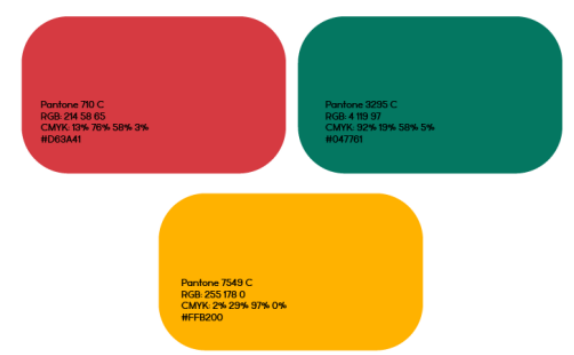

Gambar 9. Color Pallatte Produk

\subsection{Produksi}

Setelah selesai membuat logo, Selanjutnya untuk meningkatkan brand awernerness dan dikenali oleh calon konsumen maka perlu adanya media-media yang mendukung untuk produk Salad Buah "Berkah Jaya" yaitu dengan membuat brand identity. Hal yang dibuat adalah media promosi baik online maupun offline.

4.5.1 Kartu Nama dan Banner

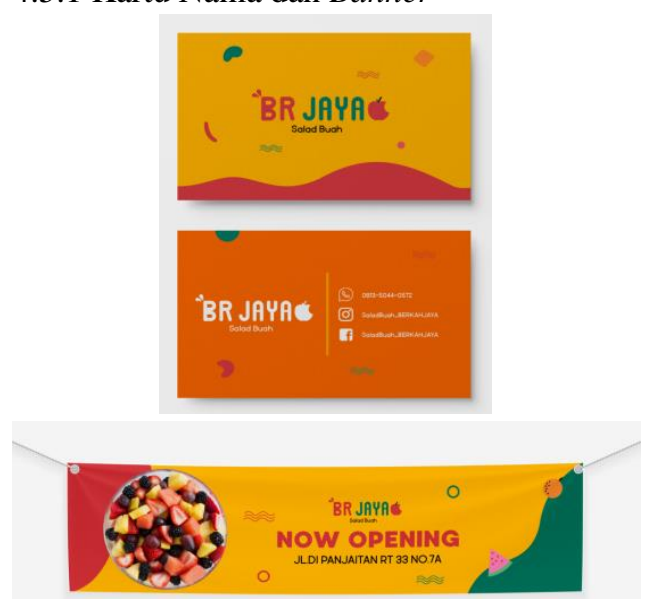

Gambar 10. Kartu Nama dan Banner

4.5.2 Celemek dan Topi 

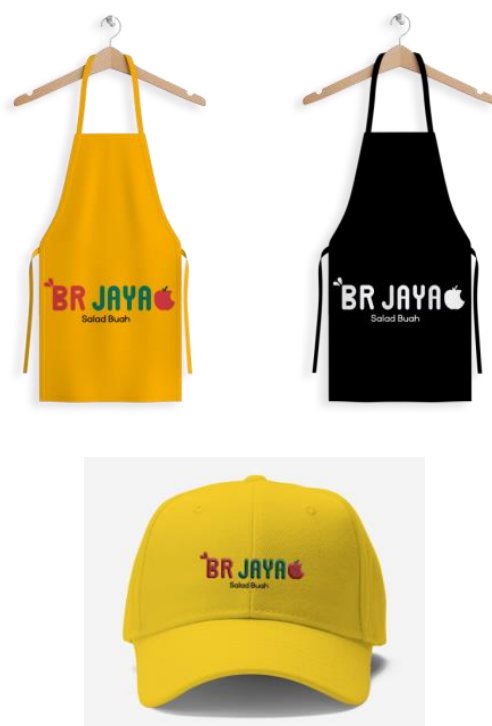

Gambar 11. Apron dan Topi

\subsubsection{Daftar Menu dan Kemasan}

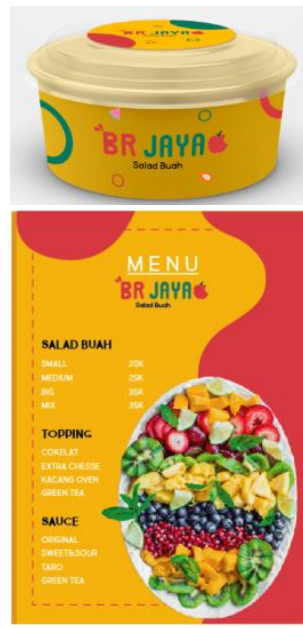

Gambar 12. Daftar Menu dan Kemasan 4.5.3 Sendok dan Garpu

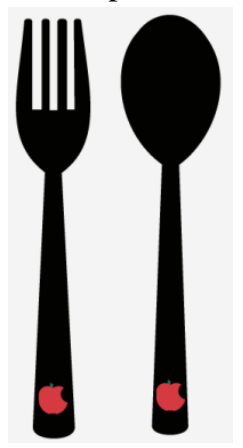

Gambar 13. Sendok dan Garpu

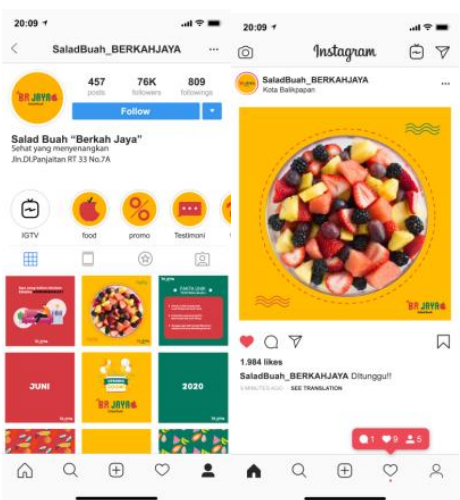

Gambar 14. Instagram

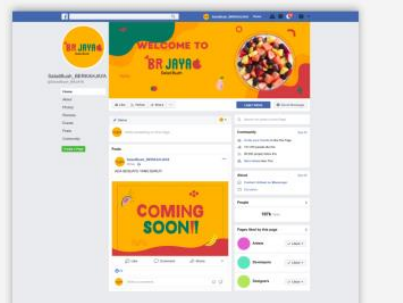

Gambar 15. Facebook

4.5.5 Website dan Brosur
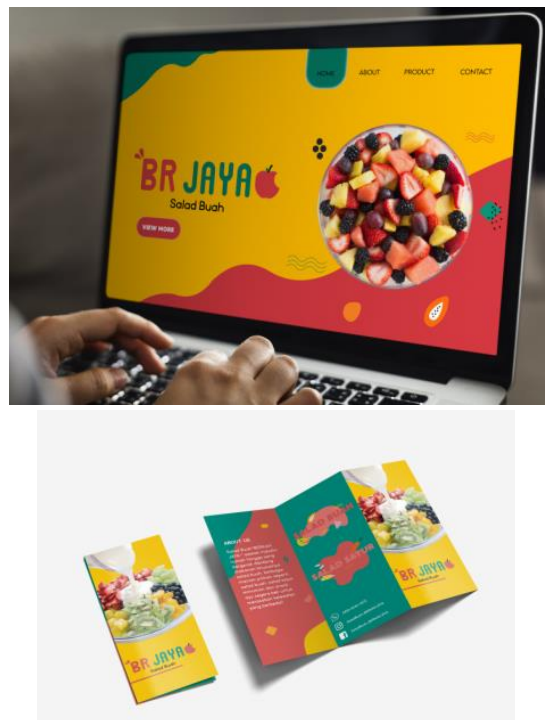

Gambar 16. Website dan Brosur

4.5.6 Totebag 


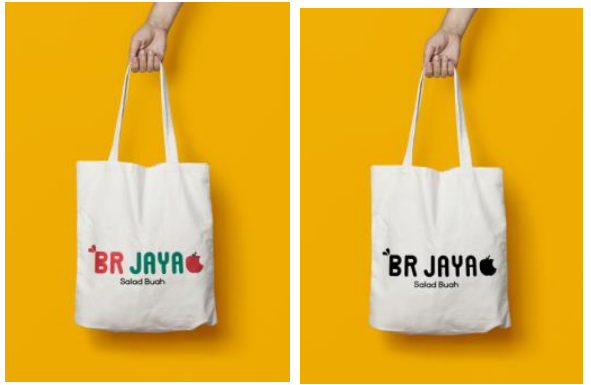

Gambar 17. Totebag

\subsubsection{Stamp dan Outlet}
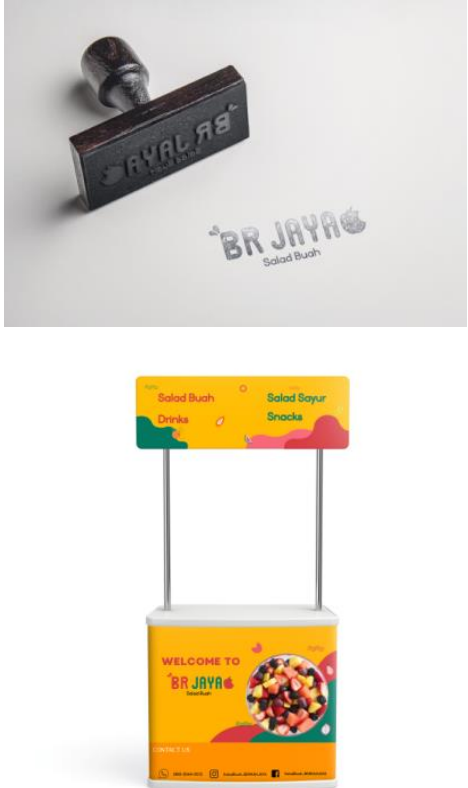

Gambar 18. Stamp dan Outlet

4.5.8 Vehicle Identity dan Signage
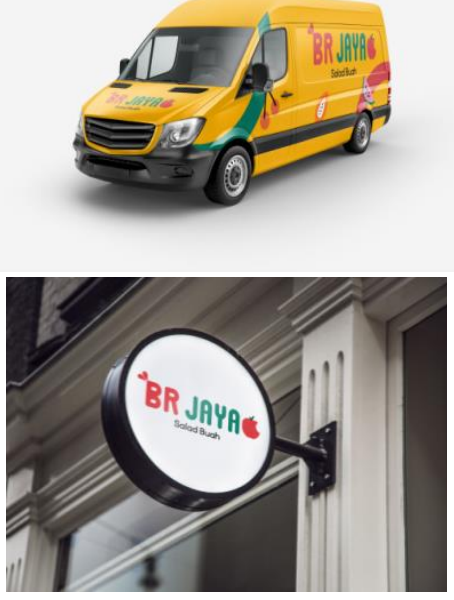

Gambar 19. Vehicle Identity dan Signage

4.5.9 Nota Pembelian

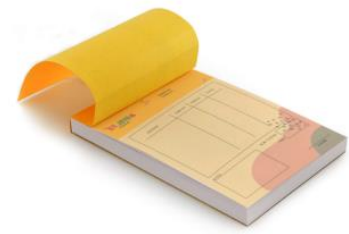

Gambar 20. Nota Pembelian

4.5.10 X-banner

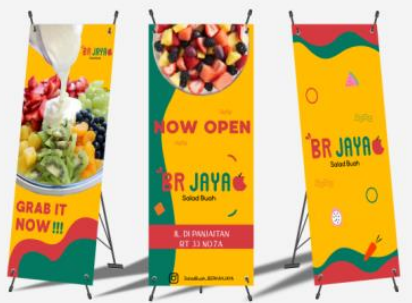

Gambar 21. X-banner

4.5.11 Toilet Sign dan Staff Sign
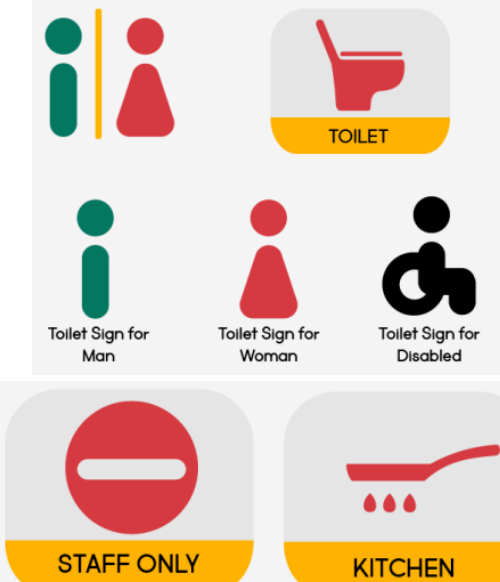

KITCHEN

Gambar 22. Toilet Sign dan Staff Sign

4.5.12 Parking Sign 


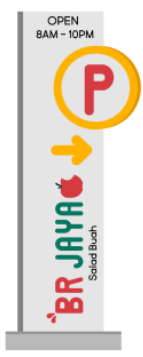

Gambar 23. Parking Sign

\subsubsection{Smoking Area Sign}

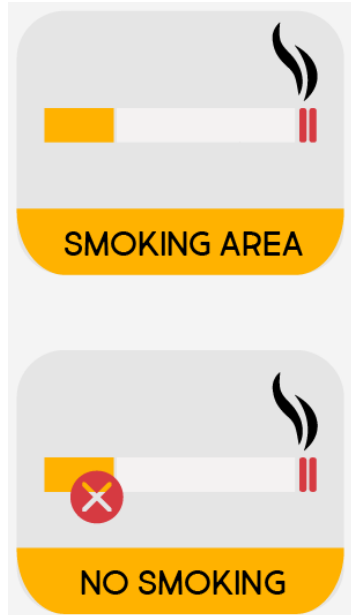

Gambar 23. Smoking Area Sign

\subsubsection{Arrow Sign}

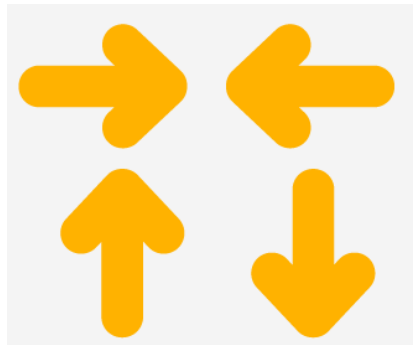

Gambar 24. Arrow Sign

4.5.15 ID Badge

\section{"BR JAYAC's Havanda}

\section{BR JAYACS Havanda}

\section{Gambar 25. ID Badge}

\subsection{Pasca Produksi}

Setelah selesai membuat mockup sebagai media promosi selanjutnya membuat GSM(Graphic Standard Manual). Graphic Standard Manual merupakan upaya untuk menjaga keseragaman identitas perusahaan. Graphic Standard Manual ini akan menjadi panduan dalam mengelola tampilan identitas perusahaan. Keseragaman tampilan identitas baik dari tampilan sarana, elemen komunikasi maupun elemen promosi dalam menjaga dan meningkatkan citra perusahaan.

Tabel 1. List Graphic Standard Manual

\begin{tabular}{|c|c|c|}
\hline Chapter & Judul & Keterangan \\
\hline - & Introduction & $\begin{array}{l}\text { Pengenalan } \\
\text { terhadap buku } \\
\text { GSM dan } \\
\text { tujuannya }\end{array}$ \\
\hline- & Content & Daftar Isi \\
\hline \multirow{4}{*}{1} & Brand History & $\begin{array}{l}\text { Awal mula dari } \\
\text { sebuah brand } \\
\text { Salad Buah } \\
\text { "Berkah Jaya" }\end{array}$ \\
\hline & $\begin{array}{l}\text { Vission and } \\
\text { Mission }\end{array}$ & $\begin{array}{l}\text { Visi dan misi } \\
\text { Salad Buah } \\
\text { "Berkah Jaya" }\end{array}$ \\
\hline & Brand Value & $\begin{array}{l}\text { Nilai-nilai yang } \\
\text { diberikan oleh } \\
\text { Salad Buah } \\
\text { "Berkah Jaya" }\end{array}$ \\
\hline & $\begin{array}{l}\text { Brand } \\
\text { Positioning }\end{array}$ & $\begin{array}{l}\text { Target market } \\
\text { yang } \\
\text { dikhusukan } \\
\text { untuk Salad } \\
\text { Buah "Berkah } \\
\text { Jaya" }\end{array}$ \\
\hline & Logo Concept & $\begin{array}{l}\text { Konsep logo } \\
\text { secara singkat }\end{array}$ \\
\hline & Logo Element & $\begin{array}{l}\text { Elemen yang } \\
\text { digunakan pada } \\
\text { logo }\end{array}$ \\
\hline & $\begin{array}{l}\text { Logo } \\
\text { Configuration }\end{array}$ & $\begin{array}{l}\text { Pembeda antara } \\
\text { logogram dan } \\
\text { logotype }\end{array}$ \\
\hline & $\log o$ & Sistem \\
\hline
\end{tabular}




\begin{tabular}{|c|c|c|}
\hline \multirow[t]{7}{*}{2} & Construction & $\begin{array}{l}\text { yang diterapkan } \\
\text { dalam } \\
\text { logogram dan } \\
\text { logotype }\end{array}$ \\
\hline & Secure Area & $\begin{array}{l}\text { Penggunaan } \\
\text { ruang kosong } \\
\text { yang berada } \\
\text { diluar logo }\end{array}$ \\
\hline & Minimun Size & $\begin{array}{l}\text { Besaran } \\
\text { minimum } \\
\text { penggunaan } \\
\text { logo dalam } \\
\text { media aplikasi } \\
\text { maupun cetak. }\end{array}$ \\
\hline & Desain Font & $\begin{array}{l}\text { Font yang bisa } \\
\text { digunakan } \\
\text { untuk beberapa } \\
\text { media aplikasi. }\end{array}$ \\
\hline & Color Pallatte & $\begin{array}{l}\text { Kode Warna } \\
\text { yang digunakan } \\
\text { dalam logo } \\
\end{array}$ \\
\hline & $\begin{array}{l}\text { Color Usage } \\
\text { BW/Greyscale }\end{array}$ & $\begin{array}{l}\text { Penggunaan } \\
\text { warna hitam } \\
\text { putih dan abu- } \\
\text { abu dalam logo }\end{array}$ \\
\hline & $\begin{array}{l}\text { Incorrect } \\
\text { Usage }\end{array}$ & $\begin{array}{l}\text { Penggunaan } \\
\text { logo yang salah } \\
\text { dan tidak boleh } \\
\text { dilakukan }\end{array}$ \\
\hline & $\begin{array}{l}\text { Corporate } \\
\text { typeface }\end{array}$ & $\begin{array}{l}\text { Jenis font yang } \\
\text { digunakan }\end{array}$ \\
\hline 3 & Supergraphic & $\begin{array}{l}\text { Visual elemen } \\
\text { yang digunakan } \\
\text { dengan bentuk- } \\
\text { bentuk abstrak }\end{array}$ \\
\hline 4 & $\begin{array}{l}\text { Media } \\
\text { Application }\end{array}$ & $\begin{array}{l}\text { Aturan berupa } \\
\text { ukuran, bahan, } \\
\text { dan contoh } \\
\text { brand identity, } \\
\text { merchandise, } \\
\text { signage, dan } \\
\text { lain-lain }\end{array}$ \\
\hline
\end{tabular}

Dari list yang telah dibuat, maka dilanjutkan proses pengaturan tata letak buku Graphic Standard Manual. Buku ini dirancang menggunakan grid system untuk mengatur besaran jarak antar kolom yang konsisten.

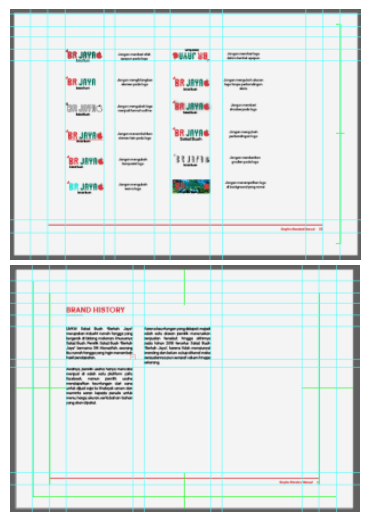

\section{Gambar 25. Proses Layout Buku GSM}

Semua hasil akhir dari perancangan ini akan dipamerkan secara online melalui media instagram dengan format multiple post berjumlah 10 konten. Konten tersebut berisi 1 video berdurasi 1 menit dan 9 buah foto hasil akhir dari perancangan ini.

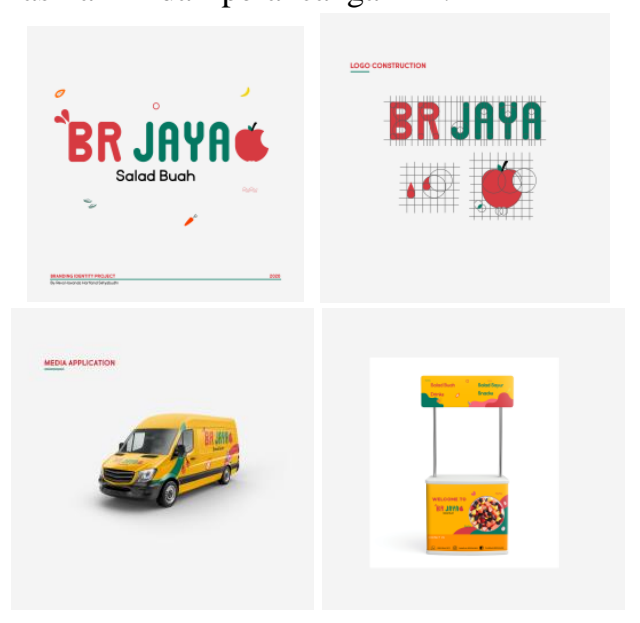

Gambar 26. Pameran Online

\section{KESIMPULAN}

Setelah melalui rangkaian proses dalam mengerjakan tugas akhir "Perancangan Brand Identity Sebagai Media Promosi untuk UMKM "Berkah Jaya" Salad Buah dapat diambil kesimpulan bahwa dalalm kebutuhan sehari-hari yang semakin padat banyak sekali aktivitas yang dilakukan oleh setiap orang dan membutuhkan makanan yang bermanfaat bagi kesehatan. Masyarakat saat ini berusaha untuk mengkonsumsi makanan sehat dan menjadi kebiasaan agar badan tetap fit dan menjaga kesehatan. Salah 
satu makanan sehat yang aman dikonsumsi dalah salad, baik itu salah buah maupun salad sayur. serta dalam penerapan promosi. Proses perancangan ini menggunakan metode kualitatif deskriptif dengan pengumpulan data yang terbagi menjadi dua bagian yaitu data primer dan data sekunder. Data primer dimulai dari observasi, wawancara, dan kuisioner dan data sekunder dimulai dari studi pustaka dan dokumnetasi. Berdasarkan hasil dari pengumpulan data yang dilakukan dianalisis kembali menggunakan analisis SWOT dan matriks SWOT dengan menentukan strategi yang dilakukan yang dapat mempengaruhi "Berkah Jaya" Salad Buah. Selanjutnya dilakukan membuat brand brief sebagai acuan agar proses yang dilakukan sesuai dengan tujuan. Hasil yang didapatkan dari perancangan ini berupa brand identity dari logo baru "Berkah Jaya" Salad Buah, media promosi yang digunakan hingga buku GSM (Graphic Standard Manual) sebagai buku panduan dari perusahaan.

\section{DAFTAR PUSTAKA}

Dirjen Haki dalam Rustan, Surianto,2013. Mendesain Logo. Jakarta: Gramedia Pustaka Utama

Ghazali, Z., 2015. Perancangan Visual Branding Kawasan Agrowisata Condet (Doctoral dissertation, Institut Seni Indonesia Yogyakarta).

Prihandono, G., 2013. Perancangan Corporate Identity dan Aplikasinya Bagi Objek Wisata Ranu Klakah di Kabupaten Lumajang. SKRIPSI Jurusan Seni dan Desain-Fakultas Sastra UM.

Purba, Y.N., 2015. Perancangan Branding Lokananta Sebagai Digital Library Pertama Museum Di Indonesia (Doctoral dissertation, Institut Seni Indonesia Yogyakarta).
Rangkuti, F. 2006. Analisis SWOT Teknik Membedah Kasus Bisnis. Jakarta (ID): Gramedia Pustaka Utama

Rangkuti, F., 2015. Teknik Membedah Analisis SWOT. Jakarta: PT Gramedia Pustaka Utama.

Riadi, M., 2013. Strenghts, Weakness, Opportunities, Threats (SWOT). Retrieved Maret, 1, p.2018.

Tanuatmadja, Y. and Raditya, A., 2014. Perancangan Branding" Marilyn's Cake" Surabaya. Jurnal DKV Adiwarna, 1(4), p.12.

https://www.ukmindonesia.id/bacaartikel/ 62

Diakses 16 Februari 2020

https://kaltim.bps.go.id/pressrelease/2017/02 /06/238/pertumbuhan-ekonomi-provinsikalimantan-timur-triwulan-iv-2016.html Diakses 16 Februari 2020

https://diswaykaltim.com/2019/11/19/pertu mbuhan-umkm-di-balikpapan-hampir-7persen/

Diakses 16 Februari 2020

http://www.depkop.go.id/uploads/laporan/15 58328991_Rumusan\%20Rakornas\%20KUM KM\%202019\%20\%20Lengkap\%2010\%20Mei\%202019\%20\%20Final\%20with\%20Cover.pdf

Diakses 9 Maret 2020 